\title{
Incorporating Structural Models into Research on the Social Amplification of Risk: Implications for Theory Construction and Decision Making
}

\author{
William J. Burns, ${ }^{1,2}$ Paul Slovic, ${ }^{3}$ Roger E. Kasperson, ${ }^{4}$ Jeanne X. Kasperson, ${ }^{4,5}$ \\ Ortwin Renn, ${ }^{6}$ and Srinivas Emani ${ }^{4}$
}

Received August 24, 1992; revised August 9, 1993

\begin{abstract}
A comprehensive approach to managing risk must draw on both the descriptive insights of the behavioral sciences and the prescriptive clarity of the management sciences. On the descriptive side, this study develops structural models to explain how the impact upon society of an accident or other unfortunate event is influenced by the physical consequences of the event, perceived risk, media coverage, and public response. Our findings indicate that the media and public response play crucial roles in determining the impact of an unfortunate event. Public response appears to be determined by perceptions that the event was caused by managerial incompetence and is a signal of future risk. On the prescriptive side, we briefly discuss how these findings based upon structural models can be incorporated into a decision-analytic procedure known as an influence diagram.
\end{abstract}

Risk perception; social amplification; impact analysis; structural models; influence diagram.

\section{INTRODUCTION}

Risk research in the social sciences has developed along two important but distinct paths. Behavioral scientists have sought to describe how people and institutions perceive and respond to risk, while management scientists have attempted to develop methods that prescribe appropriate actions for managers to take. Despite significant progress in these separate areas, there is still no comprehensive approach that integrates our understanding of how a society experiences risk with formal methods of decision-making (e.g., cost-benefit analysis and decision analysis). Managers continue, for example, to be surprised and dismayed when "minor events," as

\footnotetext{
1 Department of Marketing, PHBA, University of Iowa, Iowa City, Iowa 52242.

${ }^{2}$ To whom all correspondence should be addressed.

${ }^{3}$ Decision Research, 1201 Oak St., Eugene, Oregon 97401.

${ }^{4}$ Clark University, Center for Technology, Environment, and Development (CENTED), 950 Main Street, Worcester, Massachusetts 01610.

${ }^{5}$ Brown University, Alan Shawn Feinstein World Hunger Program.

${ }^{6}$ Center of Technology Assessment, Nobelstrasse 15, D- 70, Stuttgart, Germany.
}

assessed by experts, spark great alarm and subsequent societal disruption.

A comprehensive approach to managing risk must draw upon the descriptive insights of the behavioral sciences and the prescriptive strengths of the management sciences. Formal analytic methods, for example, typically have assessed the impact of accidents or other adverse events in terms of expected loss of life or property damage. The contribution of these methods has been to provide risk managers with explicit guidance, using criteria that are well defined. A nice illustration of these methods can be seen in Keeney, ${ }^{(1)}$ who develops a utility model for evaluating potential fatalities and associated uncertainties of occurrence. The effect of fatalities on the public is evaluated in terms of the direct personal impacts of suffering and economic hardship and the indirect societal impacts of possible political and economic turmoil. Keeney's disaggregation of impacts into personal and societal is insightful, and his approach leads to clear recommendations for action. However, focusing on fatalities or related criteria may not adequately anticipate public concerns as perceptions of threat and social response appear less a matter of physical outcomes than of attitudes, social influences, and cultural identity. ${ }^{(2)}$ 
Research from multiple disciplines may help broaden the criteria considered by prescriptive methods. Psychometric research, ${ }^{\left({ }^{3}\right)}$ for instance, has identified numerous factors that appear related to perception and acceptance of risk, such as voluntary exposure, controllability, familiarity, and perceived catastrophic potential. Sociological analysis has examined social and organizational factors that influence risk experiences, ${ }^{(4,5)}$ the capability of risk management institutions to cope with large-scale risks, ${ }^{(6,7)}$ and perceived equity in the distribution of risks and benefits. ${ }^{(8,9)}$

Providing managers with a better understanding of how society perceives and responds to risk will help managers make more informed decisions. Likewise, developing better prescriptive strategies will also contribute to improved risk decisions even if these strategies largely ignore societal perceptions. The challenge, however, is to draw on the knowledge, theories, and methodological tools of each perspective to provide risk managers with comprehensive and well-formulated recommendations.

Our paper discusses methodological and theoretical developments in the social sciences that may contribute to a more comprehensive approach to risk management. It also describes, briefly, how these developments can be combined with more formal methods of risk analysis.

\section{MODELING THE SOCIAL AMPLIFICATION OF RISK: AN EXAMINATION OF A HAZARD DATA BASE USING STRUCTURAL MODELS}

\subsection{Description of Theory and Relationships Among Model Constructs}

Aiming to link the technical assessment of risk with psychological and cultural perspectives on risk-relateu behavior, Kasperson et al. ${ }^{(10)}$ proposed a theoretical framework labeled "the social amplification of risk." According to the social amplification model, the effects of an adverse event such as an accident sometimes extend far beyond the direct damages to victims, property, and environment and may result in massive indirect impacts. The theory postulates that the social and economic impacts of an adverse event are determined not only by the direct biological and physical consequences of the event, but by the interaction of powerful psychological, cultural, social, and institutional processes that amplify or attenuate public response to the event. When an event occurs, information regarding the event flows through various channels to the public and its many cultural and social groups. This information is interpreted largely on the basis of its interaction with the above processes which, in turn, triggers risk-related behavior. Such behavior, together with the influence of the media and special interest groups, generates secondary social and economic consequences that eventually call for additional institutional responses and protective actions (or, in the case of risk attenuation, eventually impede protective actions).

In the present study, we investigate the social amplification theory by developing structural models based on factors assumed to contribute to an event's impact. The theoretical models are tested using judgments obtained from samples of laypersons and experts. The factors in the models include the event's physical consequences, associated risk perception characteristics, media coverage, and ability to stimulate public response. The hypothesized relationships among these factors are depicted in Fig. 1.

In Fig. 1, Public Response (degree to which the public becomes involved with reducing a hazard's risk) and Media Coverage (volume of news coverage) are assumed to have a strong, positive, and direct effect on an event's impact. The nature of these effects is illustrated by the single-headed arrows connecting these two factors with Societal Impact. For example, the media and public may put pressure on policy-makers to increase regulation of a hazard as a result of some mishap. This could result in substantial costs to a particular firm or industry.

The Physical Consequences of an event (number of people and amount of property directly exposed to risk or actually harmed by the event) may also have a direct and positive effect on its impact. However, according to the theory, an event's physical consequences

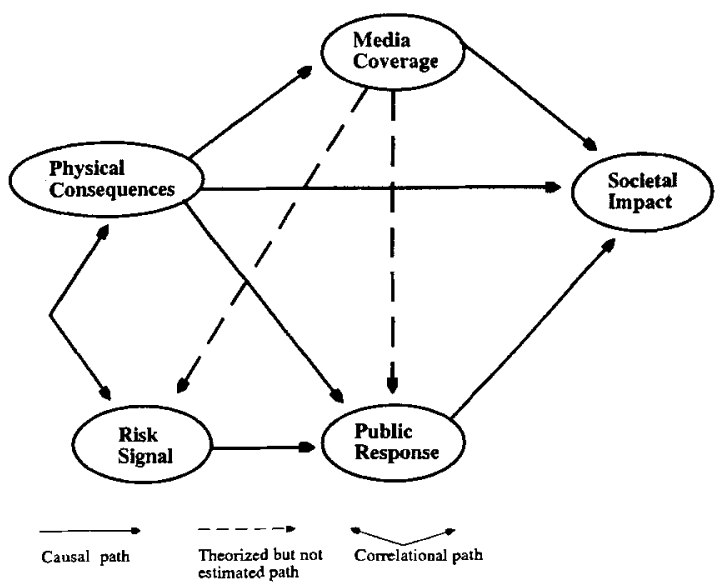

Fig. 1. Proposed model prior to interaction with data (all constructs have multiple measures). 
will have their primary influence by stimulating media coverage and public reaction. Examples of this phenomenon are events in which large numbers of people are exposed to risk, though few are actually harmed. Perceived exposure to risk may stimulate media and public attention and thus have a large indirect impact without having much direct impact.

Finally, it is hypothesized that an event's Risk Signal (degree to which an event leads the public to believe that a new risk has appeared or that the risk is different and more serious than previously thought) will have a strong, positive, and direct effect on Public Response. ${ }^{(3)}$ It is further hypothesized, however, that Risk Signal will influence an event's Societal Impact only indirectly through its ability to incite Public Response. It is expected that adverse events inspiring dread, or believed to be managed incompetently, or perceived to pose future danger to others will be viewed as high signal events and will elicit strong public reaction that in turn may affect a firm or an industry. For example, events surrounding nuclear power generally have high signal value, ${ }^{(11)}$ and this helps explain the public's reaction to the accident at Three Mile Island and to other, lesser, problems in the nuclear industry. The theory also suggests that the amount of media coverage should influence how the public perceives and responds to a hazard event. This contention is portrayed by the dashed arrows in Fig. 1. However, this influence path cannot be examined in this study because the respondents providing information on these variables were not differentially exposed to media coverage. For many respondents this survey may have represented their only exposure to an event regardless of how much media coverage it received.

\subsection{Operationalizing the Model}

In Fig. 1 we provided the general intuition behind the social amplification process and specified the expected relationships among its constructs. However, estimation and theory testing require that these abstract constructs be tied to measurable phenomena. Hence, we now describe how each construct was measured and we provide a brief discussion of the structural model investigated.

The model used to estimate the relations depicted in Fig. 1 is shown in Fig. 2, and its measured variables are discussed in Table I. For purposes of estimation, we represent an event's physical consequences by three constructs describing the size of the event (Event Scale), the number of people harmed (Casualties), and the amount of property damaged (Property Damaged). Likewise, we capture Risk Signal by Perceived Managerial Incompetence and Future Risk. Variables depicted with ovals are latent constructs and are represented by multiple measures. For example, Societal Impact is measured by an assessment of the political and economic impacts of each event. Some constructs, such as Casualties, have only one measure and are depicted with squares. Single-headed arrows imply causality, while double-headed arrows imply only correlation. Some causal paths such as from Casualties to Public Response do not appear because they were statistically insignificant and so were removed from our proposed model. The same is true for a number of correlational paths. The findings from this estimation will be discussed in a later section.

\subsection{Description and Selection of the Adverse Events Data Base}

The adverse events selected for this study included routine as well as unexpected events and included mishaps as well as reports of potential dangers. Almost all events occurred in North America during the 10-year period between 1976 and 1987. A comprehensive set of events was selected with guidance from a taxonomy of hazards suggested by Hohenemser et al. ${ }^{(12)}$ Their taxonomy characterizes hazard events as belonging to

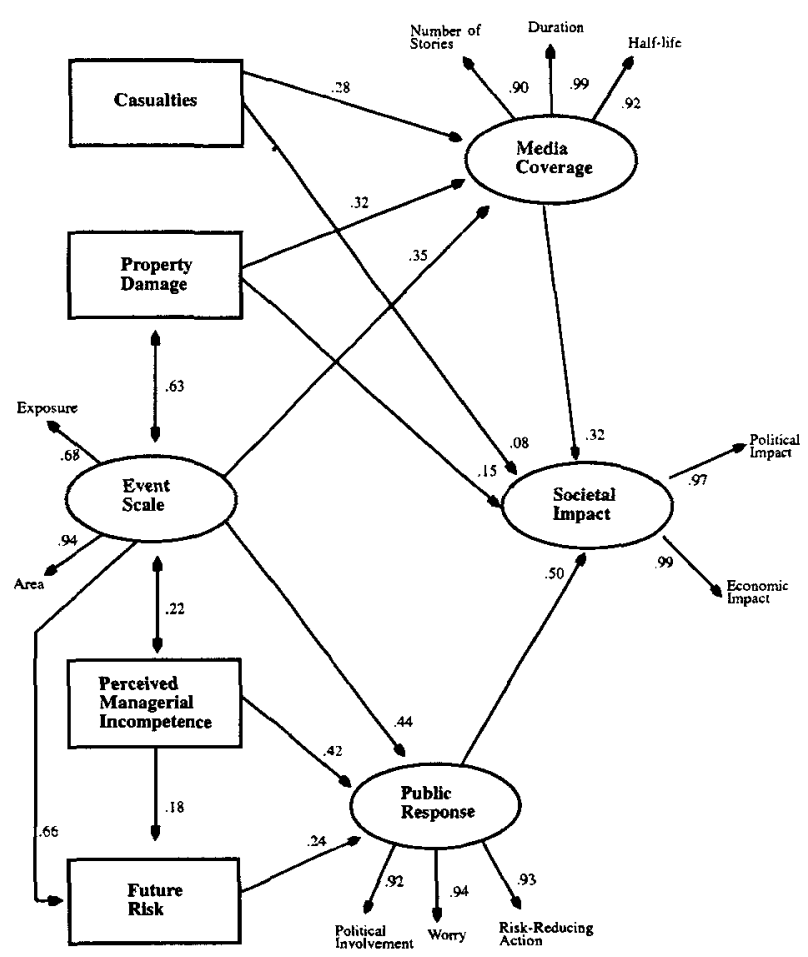

Fig. 2. Covariance structure model for sample 1. 
Table I. Description of Model Variables for Each Construct

\begin{tabular}{|c|c|}
\hline $\begin{array}{l}\text { EVENT SCALE } \\
\text { Exposure } \\
\text { Area }^{b}\end{array}$ & $\begin{array}{l}\text { The number of people exposed to harm from a hazard } \\
\text { The amount of area exposed to harm from a hazard }\end{array}$ \\
\hline $\begin{array}{l}\text { CASUALTIES } \\
\text { Casualties }^{b}\end{array}$ & The number of people injured or killed by a hazard \\
\hline $\begin{array}{l}\text { PROPERTY DAMAGE } \\
\text { Property Damage }\end{array}$ & The amount of monetary damage to property from a hazard \\
\hline $\begin{array}{l}\text { MEDIA COVERAGE } \\
\text { Nstories } \\
\text { Duration }^{c} \\
\text { Half-life }^{c}\end{array}$ & $\begin{array}{l}\text { The number of follow-up news stories reporting on a hazard } \\
\text { The number of days between the first and last news stories } \\
\text { The number of days until half the news stories appeared }\end{array}$ \\
\hline $\begin{array}{l}\text { RISK SIGNAL } \\
\text { Future Risk } \\
\text { Perceived Managerial } \\
\text { Incompetence }\end{array}$ & $\begin{array}{l}\text { Degree to which other people are at risk of experiencing harm from future hazards of this type } \\
\text { Degree to which the public believes that a hazard implies that similar risks are being managed incompetently }\end{array}$ \\
\hline $\begin{array}{l}\text { PUBLIC RESPONSE } \\
\text { Political Involvement } \\
\text { Worrye } \\
\text { Risk-Reducing Actione }\end{array}$ & $\begin{array}{l}\text { Degree to which the public is willing to become politically involved to reduce future risks posed by a hazard } \\
\text { Degree to which the public worries about the risks posed by a hazard } \\
\text { Degree to which the public is willing to become actively involved (e.g., joining an action-oriented group) to } \\
\text { reduce future risks posed by a hazard }\end{array}$ \\
\hline $\begin{array}{l}\text { SOCIETAL IMPACT } \\
\text { Political Impact } \\
\text { Economic Impact }\end{array}$ & $\begin{array}{l}\text { Degree to which a hazard generates political attention by public officials } \\
\text { Degree to which a hazard generates economic impacts (e.g, loss of sales, increased costs due to regulation) }\end{array}$ \\
\hline
\end{tabular}

five classes: Biocidal (e.g., vaccines), Persistent/Delayed effects (e.g., mercury release), Rare Catastrophes (e.g., airplane crashes), Threats to Life (e.g., smoking), and Global/Diffuse Hazards (e.g., $\mathrm{CO}_{2}$ release). Radiological Hazards (e.g., nuclear accidents) were also included.

Events representing each of the classes were identified through a search of the New York Times Index. Using this Index as a list from which to sample, events were chosen to represent a wide range of consequences pertaining to people and the environment. Within each class, effort was made to balance the distribution of recent and less-recent events. Each class had approximately the same number of events. Data were collected on 108 events and these events provided the stimuli upon which expert and public assessment was based.

Respondents received a brief news clipping for each event or report. A group of risk experts received a synopsis of the actual news story, while the nonexperts received an even briefer version of the story, omitting names and extraneous details. For example, one partic- ular news story covering the side effects of a vaccination read "Joshua Reed received his third DPT shot in Hallstead, PA. He had seizures and suffered brain damage." The modified version read "Child suffers brain damage from routine vaccination."

\subsection{Data Collection and Variable Description}

\subsubsection{Physical Consequences}

The physical consequences of an event were initially divided into two categories: consequences affecting human systems and consequences affecting nonhuman systems. Human systems consequences were measured by the number of people exposed to harm (Exposure) as well as by the severity of the harm (Casualties). Nonhuman systems were measured by the estimated area of impact (Area) and the estimated dollar amounts of damage (Property Damage). 
All four physical consequence variables were measured on a scale ranging from $1-9$, where the scale values were defined according to the guidelines given in Hohenemser et al. ${ }^{(12)}$ Ratings of each event on all four variables were obtained through a consensus on the part of three experts (a physicist, chemist, and geographer) from the Hazard Assessment Group at Clark University. Where specific references to the extent of a mishap were not reported, the experts inferred the magnitude of the consequences.

\subsubsection{Media Coverage}

Identification of suitable news stories relied upon a manual search of The New York Times Index for coverage of events representative of categories in the sevenclass taxonomy mentioned previously. The search provided index entries for all 108 hazard events. Once these stories were identified information from their index entries was used to investigate follow-up coverage in NEWS, which is a group file in the Nexis data base. From this search, abstracts were obtained with information pertaining to the number of follow-up stories covering or mentioning the event (Number of Stories), the duration of coverage for the event (Duration), and the number of days until half of the total stories on the event had appeared (Half-Life).

\subsubsection{Risk Perceptions and Public Response}

Data pertaining to people's perceptions of risk and their likely response to an adverse event were obtained using students at the University of Oregon. Scales measuring Future Risk and Perceived Managerial Incompetence were investigated to assess the domain of risk signal. To understand better how risk perceptions translate into political and economic impacts, information was sought pertaining to people's behavioral reaction to a hazard. However, it was not feasible to observe how the public would actually react, so information on their behavioral intentions was used as a proxy. Scales such as Political Involvement and Risk-Reducing Action were used instead to represent the public's response to hazard events. Respondents were asked to rate all 108 adverse events on a nine-point scale, for each of the risk perception and public response variables. Ratings for each event on each variable were then averaged across respondents to yield an aggregate score for each adverse event on a particular variable. Examples of some of these scales are provided in Table II.

\subsubsection{Societal Impact}

The amount of sociopolitical attention (Political Impact) and socioeconomic impact (Economic Impact) were both assessed by a Delphi panel consisting of 12 experts from the fields of risk analysis, journalism, law, and politics. The Delphi procedure consisted of three rounds of discussion and assessment in which three experts were randomly assigned to one of four groups for each of the rounds. Each group was asked to rate each event in terms of both Political Impact and Economic Impact on a scale of $0-10$. The scores obtained from these three rounds were averaged to provide a single score on both variables for each event.

\subsection{Model Estimation Using Covariance Structure and Partial Least-Squares Modeling}

Covariance structure and partial least squares (PLS) modeling were used to investigate the social amplification of risk framework as modeled in Fig. 2. Both these modeling tools are general multivariate procedures that allow a researcher to investigate the relationships among variables (latent or observed) of theoretical interest. These procedures augment exploratory methods such as factor analysis, multidimensional scaling, cluster analysis, and regression analysis that have been used to understand and predict public reaction to hazardous events.

Covariance structure analysis and PLS represent complementary approaches to structural equation modeling with the former being better suited for theory testing and the latter for prediction. ${ }^{(13)}$ Covariance structure modeling typically uses a full information (e.g., maximum-likelihood or generalized least-squares) estimation approach. This full information approach potentially yields very efficient parameter estimates but also requires relatively large samples and the assumption of multivariate normality. PLS uses a very different estimation approach, relying on iterative minimization of residual variance with respect to a subset of the parameters (given either fixed-point constraints or final estimates of other model parameters). ${ }^{(14)}$ This approach has the advantage of requiring neither large samples nor specific distributional assumptions if parametric statistical tests are not desired (nonparametric procedures can be used to generate standard errors and assess model 
Table II. Examples of Measures of Risk Signal and Public Response

Perceived Managerial Incompetence (Risk Signal)

In this question I'm interested in to what extent you think that those people in charge of these events or hazards are doing an adequate or competent $j o b$. Some events or types of hazards are more difficult to manage than others. Likewise, some hazards pose greater threats to general safety or well-being if not managed properly. Considering these factors, ask yourself whether this type of event or hazard is being managed competently by those in charge. Some events, all things considered, may lead you to believe that risks of this type are being managed well. While other events may lead you to believe that risks of this type are not being managed very well.

To what extent does the event or hazard referred to in this story imply that the risks of this type are being managed properly by those in charge?

It implies risks

of this type

are being

managed properly

0

1

$$
\begin{aligned}
& \text { to in this story imply that the risks of this type are being managed properly by thos } \\
& \text { It implies risks of this type } \\
& \text { are not being managed } \\
& \text { properly }
\end{aligned}
$$

To what extent are other people at risk of experiencing harm from future events of this kind?

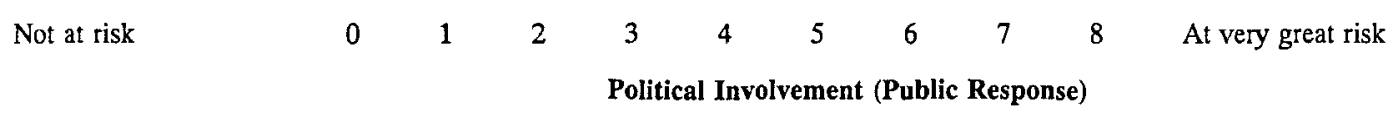

Some events concern us to the point of being willing to support political activity that would reduce future risks posed by a particular event. This involvement might take the form of signing a petition or writing letters to public officials. It could also mean donating money to or joining a political action group. While some events, though they may concern us, do not seem to have this effect on us.

To what extent would this event cause you to become politically involved with reducing the future risks posed by this hazard?

$\begin{array}{ll}\text { This event } & \text { This event would cause me } \\ \text { would not } & \text { to get very involved }\end{array}$

$\begin{array}{lllllllllll}\text { get very involved } & 0 & 1 & 2 & 3 & 4 & 5 & 6 & 7 & 8\end{array}$

adequacy), but yields less efficient estimates than maximum likelihood.

Covariance structure and PLS models possess a number of advantages for development of comprehensive theory in risk management. For example, they both are capable of incorporating an ever-expanding theoretical and empirical knowledge about how society experiences risk. This capability allows insights from many disciplines to be explicitly considered by risk managers. Likewise, these two approaches allow examination of the structural relationships among risk constructs that have emerged from exploratory procedures. They also permit an assessment of how well these constructs have been measured. Additionally, covariance structure and PLS modeling give unambiguous expression to the relative contribution of each model variable (directly or indirectly) to a dependent construct such as hazard impact. Thus, they are helpful in the construction of prescriptive models that seek to properly formulate risk decisions and estimate the probabilities of impact-related costs. ${ }^{(15)}$

\subsection{Results ${ }^{7}$}

\subsubsection{Description of Extreme Events}

A description of events scoring in the top or bottom $5 \%$ is given in Table III for a selected number of model variables. These examples suggest that an event's newsworthiness, ability to stimulate public reaction and eventual impact may have less to do with injuries or fatalities than with perceived potential to do harm. Observe, for Risk-Reducing Action that respondents indicated they would take little action to prevent fatalities resulting from an auto accident like the kind described in Table III but said they would be highly motivated to reduce the risk of a pesticide in food products. Similarly, for Perceived Managerial Incompetence the two events shown both

${ }^{7}$ A preliminary analysis of this data set has been presented by 0 . Renn, W.J. Burns, J.X. Kasperson, R.E. Kasperson, and P. Slovic in Journal of Social Issues 48, 137-160 (1992). 
represent serious hazards. However, the event depicting a voluntary effort to correct the risk falls in the lowest $5 \%$, while the other event falls in the highest $5 \%$. In this case, respondents viewed the former as demonstrating competent management. Perceptions that a firm is managing a hazard properly signal less need to worry for the future and hence less felt need to take risk-reducing action.

\subsubsection{Correlations Among Variables}

The correlations between model variables are provided in Table IV. Notice that variables measuring the same construct (enclosed), with one exception, are more correlated with each other than with other model variables. This is one indication that construct measures are performing as they should. As predicted, indicators of media coverage and public response are more related to event impact than are other model variables. Somewhat surprising is that the number of casualties has little correlation with measures of public perceptions or response. This may again suggest that indications of injuries or fatalities alone do not trigger public reaction to a hazard event.

\subsubsection{Covariance Structure Modeling}

The covariance structure model in Fig. 2 (its path coefficients and fit statistics are also provided in Table V) was estimated using a generalized least-squares procedure provided in a statistical package known as EQS. ${ }^{(16)}$

To improve estimation, the distributions of all model variables were examined for normality and variables were transformed where necessary. For example, the measures of Societal Impact and Media Coverage were reexpressed using the natural log. Multivariate normality was then assessed using Mardia's coefficient, a statistic provided by the output of EQS. Mardia's coefficient suggested the assumption of multivariate normality was plausible.

All path estimates have been standardized; as a result, causal links (one-way arrows) are represented by standardized regression coefficients and covariance links (two-way arrows) are represented by correlation coefficients. For example, the standardized path coefficient linking Media Coverage with Societal Impact is . 32 . This means that events that are one standard deviation above the mean for Media Coverage tend, on average, to be .32 standard deviations above the mean for Socie- tal Impact. Likewise, the coefficients associated with paths connecting constructs with their measurement indicators (i.e., measurement coefficients) are correlations and hence provide evidence of the relation between a construct and each of its measures. For instance, the measurement coefficients for Public Response range from $.92-.94$, indicating that they are highly correlated with the construct they are intended to measure.

The overall fit for the model in Fig. 2 was assessed by examining the $\chi^{2}$ statistic and the Bentler-Bonnet Normed Fit Index (NFI). The $\chi^{2}$ statistic $\left(\chi^{2}=90.22\right.$, $d f=67, P=.03$ ) indicated that the model fit the data only marginally well (a $P>.05$ typically is considered acceptable). However, when correlations among observed variables are high (see Table IV), the $\chi^{2}$ test will tend to indicate a lack of fit even for models that fit the data well. The NFI, which compares the fit of the model to that of a model that claims there is no underlying correlational structure, was .99 . The maximum value of the NFI is 1.00 and values over .9 are typically considered acceptable. Hence, taken together, these two indices suggest the model is reasonably consistent with the data.

The quality of measurement was investigated by examining both the size of the measurement coefficients and the tendency of measurement indicators to load on constructs other than the one they are supposed to measure. All indicators except Exposure have coefficients of .90 or above, suggesting they are highly related to their underlying constructs. There was little evidence to suggest that substantial improvements in model fit could be obtained by allowing measures, where plausible, to load on more than one construct. Hence, the model constucts appear to be measured well.

After one model revision in which insignificant paths were removed, all path coefficients in Fig. 2 are statistically significant with the exception of the coefficients for paths linking Casualties and Property Damage with Societal Impact. The marginal direct influence of these two constructs on Societal Impact is important in light of the prominent role these two variables play in risk analysis. Hence, these paths were retained despite their small effect size. As anticipated, Media Coverage and Public Response exert a strong direct influence on Societal Impact. Together, these four factors (Casualties, Property Damage, Media Coverage, and Public Response) combined explain about $62 \%$ of the variance of Societal Impact. Event Scale, Casualties, and Property Damage directly effect Media Coverage but explain only about $45 \%$ of its variance. Future Risk, Perceived Managerial Incompetence, and Event Scale appear to directly influence Public Response and ex- 
Table III. Examples of Events Scoring in Highest or Lowest $5 \%$ on a Subset of Model Variables

\begin{tabular}{|c|c|}
\hline Variable & Event score \\
\hline $\begin{array}{l}\text { 1. Exposure (range: } 1-9 \text {, mean: } 3.85 \text { ) } \\
\text { a. Low. Tractor trailer carrying } 246 \text { containers of low-level radioactive waste through Long Island City, Queens, splits } \\
\text { open as it passes below elevated subway track. No material leaked or spilled. } \\
\text { b. High. New tests and surveys suggest that potentially harmful levels of radon gas may be contaminating homes in } \\
\text { New York, New Jersey, and Pennsylvania well beyond Reading Prong information; radon is believed to cause from } \\
5000 \text { to } 20,000 \text { of } 100,000 \text { lung-cancer deaths each year in U.S.; New York State Health Commissioner, Dr. David } \\
\text { Axelrod, sees "very significant public health threat." }\end{array}$ & 1 \\
\hline $\begin{array}{l}\text { 2. Casualties (range: } 1-6 \text {, mean: 1.71) } \\
\text { a. Low. Uranium-processing plant north of Cincinnati, Ohio leaked a small cloud of radioactive uranium hexafluoride } \\
\text { gas from cracked metal cylinder, no workers injured. } \\
\text { b. High. Delta Airlines L-1011 Jumbo Jet with } 161 \text { people aboard crashes and explodes in violent thunderstorm as it } \\
\text { tries to land at Dallas-Fort Worth Airport. } 137 \text { die, } 24 \text { survivors. }\end{array}$ & 4 \\
\hline $\begin{array}{l}\text { 3. Property damage (range: } 1-9 \text {, mean: } 4.66 \text { ) } \\
\text { a. Low. Three elderly individuals went to the same health clinic in Pittsburgh to receive influenza shots. All three died } \\
\text { within } 6 \text { hr of being inoculated. } \\
\text { b. High. First state-wide study of New Jersey shows that average acidity of rain, sleet, and snow to be at least } 30 \\
\text { times greater than normal. The most highly acidic rain comes from storms that contain winds coming from the } \\
\text { Northwest section of the country, where much } \mathrm{SO}_{2} \text { is emitted. }\end{array}$ & 1 \\
\hline $\begin{array}{l}\text { 4. Number of stories (range: } 0-2064 \text {, mean: } 94.58 \text { ) } \\
\text { a. Low. Chartered bus carrying homeless men from several cities in East and Middle West to Rajneesh religious } \\
\text { commune in Oregon collides with car. One person dies, and } 31 \text { are injured in Notus, Idaho accident. } \\
\text { b. High. Huge discharge of toxic chemicals into Rhine River confronts Europe with worst ecological disaster in recent } \\
\text { years. } 1000 \text { tons of chemicals (including } 8 \text { tons of mercury) spill into Rhine after fire in chemical storage warehouse } \\
\text { in Basel, Switzerland. }\end{array}$ & 551 \\
\hline $\begin{array}{l}\text { 5. Risk-reducing action (range: } .5-6.69 \text {, mean: } 3.32 \text { ) } \\
\text { a. Low. A van and a pickup truck collide. Five people are killed, and four are injured. } \\
\text { b. High. High levels of the cancer-causing pesticide EDB have been found in flour, pancake mixes, and other widely } \\
\text { used food products. }\end{array}$ & $\begin{array}{l}1.15 \\
5.08\end{array}$ \\
\hline $\begin{array}{l}\text { 6. Perceived managerial incompetence (range: } 1.84-7.24 \text {, mean: } 5.02 \text { ) } \\
\text { a. Low. Manufacturer announces a voluntary candy-bar recall after tests show salmonella bacteria in several batches. } \\
\text { b. High. High levels of the cancer-causing pesticide EDB have been found in flour, pancake mixes, and other widely } \\
\text { used food products. }\end{array}$ & $\begin{array}{l}2.96 \\
6.60\end{array}$ \\
\hline $\begin{array}{l}\text { 7. Future risk (range: } 2.38-6.43 \text {, mean: } 4.45 \text { ) } \\
\text { a. Low. A major dam collapses. The water released kills } 14 \text { and devastates } 1 / 2 \text { million acres of land. } \\
\text { b. High. Three hazardous waste and dump sites were recently added to four already known to exist around the same } \\
\text { harbor, and dangerous chemicals have been found to be leaking into the groundwater. }\end{array}$ & $\begin{array}{l}2.96 \\
6.01\end{array}$ \\
\hline $\begin{array}{l}\text { 8. Economic impact (range: } 0-8.5 \text {; mean: } 2.12 \text { ) } \\
\text { a. Low. Chartered bus carrying homeless men from several cities in East and Middle West to Rajneesh religious } \\
\text { commune in Oregon collides with car. One person dies, and } 31 \text { are injured in Notus, Idaho accident. } \\
\text { b. High. Times Beach, Missouri resident Lane Jumper says soil tests by Envirodyne engineers have found high } \\
\text { concentrations of dioxin and other hazardous chemicals. }\end{array}$ & 7.0 \\
\hline
\end{tabular}

plain $71 \%$ of its variance. Noteworthy is the finding that Casualties and Property Damage did not appear to directly influence Public Response. Finally, Event Scale and Perceived Managerial Incompetence directly influence Future Risk and explain $53 \%$ of its variance. All five exogenous constructs (constructs that are not causally dependent on other model variables) exert an indirect effect on Societal Impact because of their direct influence on either Media Coverage or Public Response.

To illustrate how "downstream" constructs are influenced by "upstream" constructs, the effects of predictor variables from the model in Fig. 2 were decomposed into total, direct, and indirect effects and are shown in Table VI. Based on the size of the total effects, Media Coverage and Public Response are major contributors 
Table IV. Correlations Among Model Variables from Phase I

\begin{tabular}{|c|c|c|c|c|c|c|c|c|c|c|c|c|c|c|}
\hline & 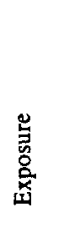 & 丞 & 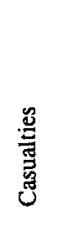 & 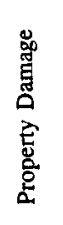 & 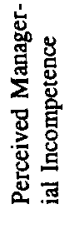 & 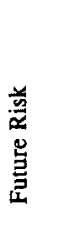 & 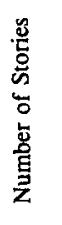 & 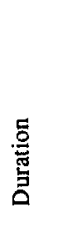 & 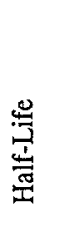 & 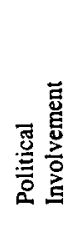 & $\stackrel{E}{5}$ & 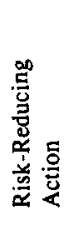 & 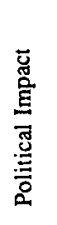 & 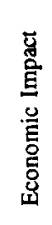 \\
\hline Exposure & & & & & & & & & & & & & & \\
\hline Area & .48 & & & & & & & & & & & & & \\
\hline Casualties & .19 & -.11 & - & & & & & & & & & & & \\
\hline Propeny Damage & .23 & .58 & .07 & - & & & & & & & & & & \\
\hline Perceived Managerial Incompetence & .25 & .16 & .06 & -.01 & - & & & & & & & & & \\
\hline Future Risk & .35 & .61 & -.10 & .41 & .31 & - & & & & & & & & \\
\hline Number of Stories & .37 & .33 & .36 & .47 & .17 & .35 & & & & & & & & \\
\hline Duration & .42 & .43 & .22 & .46 & .17 & .39 & .87 & & & & & & & \\
\hline Half-Life & .37 & .39 & .17 & .44 & .12 & .40 & .80 & .89 & & & & & & \\
\hline Political Involvement & .49 & .47 & .05 & .23 & .54 & .55 & .33 & .35 & .32 & & & & & \\
\hline Worry & .42 & .56 & -.04 & .27 & .56 & .64 & .34 & .38 & .37 & .84 & & & & \\
\hline Risk-Reducing Action & .46 & .55 & -.05 & .30 & .56 & .58 & .41 & .44 & .42 & .83 & .84 & 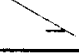 & & \\
\hline Political Impact & .46 & .34 & .30 & .39 & .40 & .41 & .65 & .63 & .51 & .57 & .54 & .59 & & \\
\hline Economic Impact & .48 & .33 & .36 & .41 & .39 & .37 & .67 & .61 & .53 & .59 & .53 & .62 & .95 & \\
\hline
\end{tabular}

to Societal Impact. Event Scale also contributes a great deal to Societal Impact but does so through these two factors as well as through Future Risk. For example, the total effect of Event Scale on Societal Impact is comprised of its indirect effects through Media Coverage, Public Response, and Future Risk. The total effect was calculated as follows:

$$
(.35)(.32)+(.44)(.50)+(.66)(.24)(.50)=.41
$$

Observe that Perceived Managerial Incompetence has a larger influence on Societal Impact than does Casualties; however, it operates through its indirect effects.

\subsubsection{Corroboration Using PLS}

To corroborate the findings of the previous model, a PLS model was estimated using the same input variables. Its path coefficients are shown in Table V. As noted previously, in situations where sample size is small and multivariate normality is violated, PLS is more robust with respect to small sample size and violations of multivariate normality than the generalized least squares procedure used in the previous model. The PLS model does not have an overall measure of fit. However, the significance of the structural and measurement paths in the PLS model was evaluated nonparametrically by computing the ratio of the jack-knifed path estimates to jackknifed standard errors. All such ratios were found to be extremely large, suggesting the viability of these paths. The measurement coefficients appear to be slightly larger than their counterparts in Fig. 2, while the structural coefficients appear in most cases smaller. Based on the evaluation criteria used under each estimation procedure and the similarity of their findings, it appears that the structure depicted in the covariance structure and PLS models works reasonably well.

To examine the statistical replicability of the covariance structure and PLS models, 12 new Delphi panelists were chosen and information was again obtained regarding the political and economic impact of a 
Table V. Model Comparisons Across Samples Using Covariance Structure and PLS Analysis

\begin{tabular}{|c|c|c|c|c|c|}
\hline & \multicolumn{2}{|c|}{ Phase 1} & \multicolumn{2}{|c|}{ Phase 2} & \multirow{2}{*}{$\frac{\text { Combined }}{\text { Covariance }}$} \\
\hline & Covariance & PLS & Covariance & PLS & \\
\hline \multicolumn{6}{|l|}{ Structural paths ${ }^{a}$} \\
\hline $\mathrm{ES} \rightarrow \mathrm{FR}^{b}$ & $.66^{c}$ & .54 & .60 & .54 & .62 \\
\hline $\mathrm{PMI} \rightarrow \mathrm{FR}$ & .18 & .19 & .24 & .28 & .24 \\
\hline $\mathrm{C} \rightarrow \mathrm{MC}$ & .28 & .24 & .13 & .24 & .24 \\
\hline $\mathrm{PD} \rightarrow \mathrm{MC}$ & .32 & .31 & .33 & .32 & .38 \\
\hline $\mathrm{ES} \rightarrow \mathrm{MC}$ & .35 & .31 & .25 & .31 & .25 \\
\hline $\mathrm{ES} \rightarrow \mathrm{PR}$ & .44 & .35 & .13 & .10 & .26 \\
\hline $\mathrm{PMI} \rightarrow \mathrm{PR}$ & .42 & .41 & .60 & .51 & .52 \\
\hline $\mathrm{FR} \rightarrow \mathrm{PR}$ & .24 & .29 & .40 & .45 & .34 \\
\hline $\mathrm{C} \rightarrow \mathrm{SI}$ & .08 & .24 & .25 & .36 & .13 \\
\hline $\mathrm{PD} \rightarrow \mathrm{SI}$ & .15 & .09 & .15 & .19 & .15 \\
\hline $\mathrm{MC} \rightarrow \mathrm{SI}$ & .32 & .35 & .39 & .29 & .39 \\
\hline $\mathrm{PR} \rightarrow \mathrm{SI}$ & .50 & .45 & .43 & .38 & .48 \\
\hline \multicolumn{6}{|l|}{ Measurement paths } \\
\hline Exposure & .68 & .82 & .58 & .83 & .66 \\
\hline Area & .94 & .90 & .96 & .89 & .94 \\
\hline No. of stories & .90 & .94 & .89 & .94 & .89 \\
\hline Duration & .99 & .97 & .97 & .97 & .98 \\
\hline Half-life & .92 & .94 & .89 & .94 & .89 \\
\hline Political involvement & .92 & .94 & .98 & .96 & .98 \\
\hline Worry & .94 & .95 & .83 & .91 & .92 \\
\hline Risk-reducing action & .93 & .94 & .89 & .94 & .95 \\
\hline Political impact & .97 & .99 & .97 & .95 & .96 \\
\hline Economic impact & .99 & .99 & .81 & .95 & .95 \\
\hline \multicolumn{6}{|l|}{ Correlational paths } \\
\hline $\mathrm{ES} \leftrightarrow \mathrm{PD}^{d}$ & .63 & .49 & .60 & .49 & .62 \\
\hline $\mathrm{ES} \leftrightarrow \mathrm{PMI}$ & .22 & .23 & .31 & .41 & .28 \\
\hline \multicolumn{6}{|l|}{ Fit indices } \\
\hline $\mathrm{X}^{2}$ & 90.20 & None & 84.70 & None & 84.10 \\
\hline$d f$ & 67.00 & & 67.00 & & 67.00 \\
\hline$P$ & .03 & & .07 & & .08 \\
\hline NFI & .99 & & .99 & & .99 \\
\hline
\end{tabular}

a Structural path abbreviations: ES, event scale; PMI, perceived managerial incompetence; C, casualties; PD, property damage; FR, future risk; PR, public response; $\mathrm{MC}$, media coverage; SI, societal impact.

$b \rightarrow$, Causality.

c All estimates have been standardized.

$d \leftrightarrow$, Correlation.

hazard. In addition, a new group of students was asked to provide information regarding risk perceptions and public response.

Covariance structure and PLS models were estimated using this new data and the results are shown in Table V. The evidence gathered from the across-sample and across-estimation method comparisons suggests that the model structure shown in Fig. 2 works reasonably well. The comparisons across samples indicate that while the substantive conclusions of the model appear to be upheld, the path estimates are in many cases different.
This could be due in part to an instability of some measures of Event Scale, Public Response, and Societal Impact construct measures.

To increase the reliability of the measures, the two samples were combined. Combining these samples appeared reasonable because both were drawn from the University of Oregon student population only 7 months apart. Model coefficients and fit statistics are once again shown in Table V. The $\chi^{2}$ statistic and the NFI for the model based on the combined sample indicate a good fit. 
Table VI. Effect Decomposition for the Combined Model

\begin{tabular}{|c|c|c|c|}
\hline Constructs & Total $^{a}$ & Direct $^{b}$ & Indirect ${ }^{c}$ \\
\hline \multicolumn{4}{|l|}{$\overline{\text { SOCIETAL IMPACT }^{d}}$} \\
\hline Casualties & $.17^{e}$ & .08 & .09 \\
\hline Property damage & .25 & .15 & .10 \\
\hline Event scale & .41 & .00 & .41 \\
\hline Perceived managerial incompetence & .23 & .00 & .23 \\
\hline Future risk & .12 & .00 & .12 \\
\hline Media coverage & .32 & .32 & .00 \\
\hline Public response & .50 & .50 & .00 \\
\hline \multicolumn{4}{|l|}{ MEDIA COVERAGE } \\
\hline Casualties & .28 & .28 & .00 \\
\hline Property damage & .32 & .32 & .00 \\
\hline Event scale & .35 & .35 & .00 \\
\hline \multicolumn{4}{|l|}{ PUBLIC RESPONSE } \\
\hline Event scale & .60 & .44 & .16 \\
\hline Perceived managerial incompetence & .46 & .42 & .04 \\
\hline Future risk & .24 & .24 & .00 \\
\hline \multicolumn{4}{|l|}{ FUTURE RISK } \\
\hline Perceived managerial incompetence & .18 & .18 & .00 \\
\hline Event scale & .66 & .66 & .00 \\
\hline \multicolumn{4}{|c|}{$\begin{array}{l}\text { a Total effect is the sum of the direct effect and the indirect effect. } \\
\text { b Direct effect is the effect due only to the predictor variable of interest. } \\
\text { - Indirect effect is the effect due to the predictor's influence on inter- } \\
\text { vening variables which in turn influence the dependent variable of } \\
\text { interest. These effects are multinlicative. }\end{array}$} \\
\hline
\end{tabular}

\section{DISCUSSION}

\subsection{Summary}

Our paper has emphasized the need for an integrated approach to risk management that combines research emerging from both the behavioral and management sciences. Addressing this need, we described two structural modeling approaches that are able to bring diverse types of risk information into a single model and that should be helpful in the construction of prescriptive models that seek to properly formulate risk decisions.

We also investigated a number of predictions implied by the social amplification of risk framework. Our findings support the contention that the behavior of the media and the public play crucial roles in determining the impact of a hazardous event. Each of these factors contributes significantly to an event's impact even when controlling for the event's scale and for harm to people and property. The physical consequences of an event also strongly influence societal impact but do so primarily through intervening variables. For example, the scale of the event exerts a strong effect on event impact but operates through its ability to stimulate media and public behavior. Likewise, the number of casualties moderately affects media behavior but has only a weak direct influence on societal impact. Perceptions of managerial incompetence influence the public's response to a hazard to a degree approaching the scale of the event. Further, public judgment about managerial competence affects societal impact to a greater extent than does the number of casualties and to a similar extent as does the amount of property damage. These findings also support the claim that risk signal, depicted as perceptions of managerial incompetence and future risk, operates through its ability to stimulate public behavior and does not directly cause event impact.

The implications of our findings suggest that focusing solely on the probability and magnitude of physical consequences may greatly underestimate the actual impact of an event. Misjudging event impact can occur, for example, by either failing to consider important exogenous variables (e.g., risk signal) or by failing to understand the paths through which these exogenous factors operate (e.g., ignoring intervening variables like media coverage). For instance, model estimates suggest that the public's assessment of how competently a hazard is being managed plays a more important role than number of casualties in predicting event impact. Thus, by concentrating only on the number of casualties it is possible to underestimate the impact of an event that causes few injuries but is perceived to represent gross managerial incompetence. Likewise, though the total effect of scale, casualties, and property damage on event impact is substantial, the direct effect of each is much smaller. Hence, ignoring intervening factors like media coverage and public response may cause forecasts of event impact to be inaccurate.

Understanding how people perceive different types of hazards may not only improve predictions of impact but may mitigate long-term consequences by fostering communication between risk managers and the public. The theory of risk amplification predicts that the societal cost of a hazardous event is determined, to a large extent, by what the event signals or portends. The findings of this study support the conclusion that when an event implies that the hazard is improperly managed or that the future risk is great, the public and its representatives will act to reduce this threat. The public in a sense examines the significance of the event while formulating behavioral intentions to tolerate the risk or take actions 
against the risk and perhaps against those in charge of the risk. Lack of evidence linking the number of casualties and the amount of property damage to public response suggests the public does not use this information alone as a cue to action. However, the public does seem sensitive to the scale of the event, particularly events affecting large areas. The scale of an event may, in the public's mind, be more diagnostic of personal risk than reports of the number of casualties. The Tylenol poisonings represent a potent example of public reaction to an event that is perceived as exposing large numbers of people to danger despite the fact that relatively few people were harmed. Mitchell ${ }^{(17)}$ examined the effect of these poisonings on the stock prices of Johnson \& Johnson, Inc. and estimated a loss of $\$ 2.11$ billion to shareholders. He placed the losses realized by other over-the-counter drug companies at about $\$ 4.06$ billion.

\subsection{Study Limitations}

The risk events in this study were not selected randomly but were chosen in accord with the taxonomy suggested by Hohenemser et al. ${ }^{(12)}$ As a result, we cannot rely on sampling theory to assess how close the sample covariance matrix conforms to some population matrix. However, the Hohenemser taxonomy is a reasonable representation of the world of hazards, and the model variables were approximately normally distributed across the chosen events. Even so, generalizations beyond this sample must be made cautiously and model estimates should be treated as more descriptive of sample characteristics than inferential of population parameters.

While this study has examined variables indicative of risk signal-namely, perceptions of managerial incompetence and future risk -inclusion of other variables such as dread or familiarity may lead to a fuller portrayal of risk signal. Perceptions of managerial incompetence and threat from future risk are powerful motifs but may represent higher-order concerns relative to signals such as dread.

Public response has been measured in this study by variables representing behavioral intentions. According to Ajzen and Fishbein, ${ }^{(18)}$ the immediate antecedent of any behavior is the intention to perform the behavior in question. However, more research is needed to determine how well intentions predict public response to risk. Similarly, the behavioral intentions university students display toward a hazardous event may be different than those of the general population.

The amplification of risk framework depicts the media as a potential amplification source and hence, the media is predicted to exert a strong influence on people's perception of risk and their likely response. However, we were unable to examine this assertion because our survey may have been the only exposure respondents had to many of these events. Failure to capture these important influences undoubtedly affected our path estimates. The most likely effect was to overestimate the direct influence of media coverage on event impact. Event impact itself was only assessed by means of Delphi judgments. Better modeling and analysis of impact is needed.

\subsection{Prescriptive Implications}

Understanding factors that contribute to the impact of a hazardous event and marshalling this insight to promote sound decision strategies will become increasingly important for risk managers. We have restricted our attention to structural models; however, Burns and Clemen $^{(15)}$ have shown how to convert a causal model to a decision analytic technique known as a Gaussian influence diagram. ${ }^{(19)}$ Influence diagrams provide a vehicle for incorporating decision and criterion variables into a structural model, thus allowing the decision maker to move from a purely descriptive portrayal of the environment to a prescriptive analysis of the decision situation. In addition, the decision-analysis perspective can be of value in the early stages of developing the structural model by helping the researcher to identify and focus on issues important to decision makers. Hence, structural models and influence diagrams can be used in tandem to provide a more comprehensive approach to the management of risk.

\section{ACKNOWLEDGMENTS}

We are grateful to Bob Clemen, Claes Fornell, and Bob O'Brien for their advice and comments on this study. This research was supported by the National Science Foundation under grants SES 8912104 and SES 8915711.

\section{REFERENCES}

1. R. Keeney, "Evaluating Alternatives Involving Potential Fatalities," Operations Research 28, 188-205 (1980).

2. S. Krimsky and D. Golding, Theories of Social Risk (Westport, Connecticut, Praeger-Greenwood, 1992).

3. P. Slovic, "Perception of Risk,"' Science 236, 280-285 (1987).

4. L. Clarke, Acceptable Risk: Making Decisions in a Toxic Environment (Berkeley, California, University of California Press, 1989).

5. B. Wynne, "Misunderstood Understanding: Social Identities and 
Public Uptake of Science," Public Understanding of Science 1, 281-304 (1992).

6. C. Perrow, Normal Accidents: Living with High Risk Technologies (New York, Basic Books, 1984).

7. W. Freudenburg, The Organizational Attenuation of Risk Estimates (Paper presented at the Society for Risk Analysis Meeting, San Francisco, October/November 1989).

8. R. Kasperson and J. Kasperson, "Determining the Acceptability of Risk: Ethical and Policy Issues," in J. Rogers and D. Bates (eds.), Assessment and Perception of Human Health (Ottawa, Royal Society of Canada, 1983), pp. 135-155.

9. S. Rayner and R. Cantor, "How Fair Is Safe Enough? The Cultural Approach to Societal Technology Choice," Risk Analysis 7, 3-9 (1987).

10. R. E. Kasperson, O. Renn, P. Slovic, H. S. Brown, J. Emel, R. Goble, J. X. Kasperson, and S. Ratick, "The Social Amplification of Risk: A Conceptual Framework," Risk Analysis 8, 177187 (1988).

11. P. Slovic, "Perception of Risk from Radiation," in W. K. Sinclair (ed.), Proceedings of the Twenty-fifth Annual Meeting of the National Council on Radiation Protection and Measurements, Vol. 11: Radiation Protection Today: The NCRP at Sixty Years (Bethesda, Maryland, NCRP, 1990), pp. 73-97.
12. C. Hohenemser, R. W. Kates, and P. Slovic, "The Nature of Technological Hazard," Science 220, 378-384 (1983).

13. J. C. Anderson and D. W. Gerbing, "Structural Equation Modeling in Practice: A Review and Recommended Two-Step Approach," Psychological Bulletin 103, 411-423 (1988).

14. C. Fornell, "A Second Generation of Multivariate Analysis: Classification of Methods and Implications for Marketing Research," in M. J. Houston (ed.), The Review of Marketing 87: Section 6 (Chicago, American Marketing Association, 1987), pp. 407-450.

15. W. J. Burns and R. T. Clemen, "Covariance Structure Models and Influence Diagrams," Management Science 39 816-834 (1993).

16. P. Bentler, EQS Structural Equations Program Manual, Version 3.0 (Los Angeles, California, BMDP Statistical Software, 1989).

17. M. L. Mitchell, "The Impact of External Parties on Brand-Name Capital: The Tylenol Poisonings and Subsequent Cases," Economic Inquiry 27, 601-618 (1989).

18. I. Ajzen and P. Fishbein, Understanding Attitudes and Predicting Social Behavior (Englewood Cliffs, New Jersey, Prentice Hall, 1980).

19. R. Shachter and C. Kenley, "Gaussian Influence Diagrams," Management Science 35, 527-550 (1989). 